\title{
Role of Asp37 in metal-binding and conformational change of ciliate Euplotes octocarinatus centrin
}

\author{
Wen Liu' ${ }^{1}$, Lian Duan ${ }^{1}$, Bing Zhao ${ }^{1}$, Ya-Qin Zhao ${ }^{1}$, Ai-Hua Liang ${ }^{2}$, Bin-Sheng Yang ${ }^{1 *}$ \\ ${ }^{1}$ Key Laboratory of Chemical Biology and Molecular Engineering of Ministry of Education, Institute of Molecular Science, Shanxi \\ University, Taiyuan, China; yangbs@sxu.edu.cn \\ ${ }^{2}$ Key Laboratory of Chemical Biology and Molecular Engineering of Ministry of Education, Institute of Biotechnology, Shanxi Uni- \\ versity, Taiyuan, China
}

Received 24 December 2009; revised 18 January 2010; accepted 21 January 2010.

\begin{abstract}
Centrin is a member of the EF-hand super family that plays critical role in the centrosome duplication and separation. To investigate the role of Asp37 in the process of metal-binding and conformational change of ciliate Euplotes octocarinatus centrin (EoCen), the mutant D37K, in which aspartic acid 37 had been replaced by lysine, was first obtained by the site-directed mutagenesis. Then 2-p-toluidinylnaphthalene-6sulfonate (TNS) was used as a fluorescence probe to detect the conformational change of the protein. The results show that the metalbinding capability of the site I of EoCen was lost by the mutation of Asp37 $\rightarrow$ Lys. In comparison the $\mathrm{Tb}^{3+}$-saturated EoCen, the hydrophobic surface of D37K, which is exposed by the binding of $\mathrm{Tb}^{3+}$, has shrunk sharply, suggesting that Asp37 plays an important role in maintaining the proper conformation of EoCen in the presence of $\mathrm{Tb}^{3+}$. Meanwhile, the conditional binding constants of TNS with $\mathrm{Tb}^{3+}$-loaded EoCen and D37K were obtained, $\mathrm{K}\left(\mathrm{Tb}^{3+}\right.$-EoCen-TNS $)=(7.38$ $\pm 0.25) \times 10^{5} \mathrm{M}^{-1}$ and $\mathrm{K}\left(\mathrm{Tb}^{3+}-\mathrm{D} 37 \mathrm{~K}-\mathrm{TNS}\right)=(1.16 \pm$ $0.05) \times 10^{6} \mathrm{M}^{-1}$.
\end{abstract}

Keywords: Centrin; Aspartic Acid; $\mathrm{Tb}^{3+}$; TNS

\section{INTRODUCTION}

Centrin is a calcium-binding protein of $\sim 20 \mathrm{kDa}$, and present in both the pericentriolar material and the centrioles of centrosome. Genetic studies show that centrin is essential to normal cell cycle-dependent duplication and segregation of the microtubule organizing center (MTOC) [1]. The microtubule organizing center (MTOC) is cytoplasmic organelles, encountered in almost all the eukaryotic cells and having an important role in the nu- cleation of the microtubules and the regulation of their dynamics [2]. It is fundamental to many cellular processes, including chromosomal segregation, cytokinesis, fertilization, cellular morphogenesis, cell motility, and intracellular trafficking [3]. Much research has focused on these functions, because abnormal centrosome duplication may lead to chromosomal instability and then cancer, an idea supported by discovery of supernumerary abnormal centrosomes in different human tumor cells [4-6]. In addition, centrin forms part of the human heterotrimetric DNA damage recognition complex required for global genome nucleotide excision repair [7]. Centrin seems to act as a $\mathrm{Ca}^{2+}$ sensor, i.e., in its $\mathrm{Ca}^{2+}$-load form, centrin interacts with specific target protein to modulate the cellular activity. In general, the binding of $\mathrm{Ca}^{2+}$ involves a structural rearrangement of the $\alpha$-helices of the EF-hand pair domain with the consequent exposure of a hydrophobic cleft $[8,9]$. Conformational changes are intrinsic to the function of a variety of proteins. 2-p-Toluidinylnaphthalene-6-sulfonate (TNS) has been extensively used in the conformational change of centrin induced by metal ions [10-12].

Ciliate Euplotes octocarinatus centrin (EoCen) is a protein of 168 residues, which shares about 60,62 and $66 \%$ sequence identity with human centrin 1 , human centrin 2 and human centrin 3, respectively, and shares approximately $50 \%$ sequence identity with the well studied EF-hand protein calmodulin (CaM). Like CaM, centrin consists of two independent domains tethered by a flexible linker, each domain comprising a pair of EF-hand motifs of helix-loop-helix that can potentially bind two calcium ions [13]. As show in Figure 1 [14], the first amino acid of $\mathrm{Ca}^{2+}$-binding 12-residue loop is aspartic acid which is highly conserved. Thus, the Asp at the first position of the loop would be expected to be important to the proper conformation and metal binding characteristics of centrin.

Lanthanides have been known for their diversity in biological effects, and the application of lanthanides in medicine has high potential. In agriculture, lanthanides 


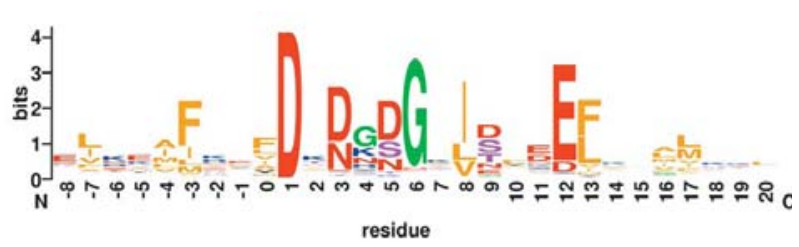

Figure 1. The sequence logo of the EF-hand domain [14]. The residues are colored as follows: $\mathrm{D}, \mathrm{E}, \mathrm{N}$, red; $\mathrm{K}, \mathrm{R}$, blue; $\mathrm{S}, \mathrm{T}$, purple; G, green; hydrophobic, yellow.

have been used to increase the production of crops and to promote the growth of livestock in China for many years [15]. The molecular mechanism of the biological effects of lanthanides is not totally understood so far. Lanthanide ions $\left(\mathrm{Ln}^{3+}\right)$ have similar ionic radii and similar coordination properties to $\mathrm{Ca}^{2+}[16]$. Hence, $\mathrm{Tb}^{3+}$ was usually used to sense properties of $\mathrm{Ca}^{2+}$-binding proteins [17].

EoCen is the first reported by our laboratory [18] (gene register Y18899), which is cloned from Euplotes octocarinatus, and the detailed biological function is unclear. In this paper, in order to investigate the importance of the first amino acid (Asp37) of site I of EoCen to the metalbinding and conformation characteristics of this protein, the mutant protein (D37K), with the mutation of Asp37 to Lys, was obtained by the method of site direct mutation. Using TNS as fluorescence probe, the characterization for the binding of $\mathrm{Tb}^{3+}$ to EoCen and the mutant $\mathrm{D} 37 \mathrm{~K}$ were investigated.

\section{MATERIALS AND METHODS}

\subsection{Reagents and Stock Solutions}

$\mathrm{N}-2$-hydroxyethylpiperazine-N-2-ethanesulfonic acid (Hepes) (analytical reagent), ampicillin (ultra pure grade), isopropyl- $\beta$-D-thiogalactoside (IPTG) (ultra pure grade), tryptone, and yeast extract were purchased from Bio. Basic Inc. TNS was bought from Sigma. Glutathione Sepharose TM 4B (GST) was purchased from Pharmacia Ltd. Terbium oxide was $99.99 \%$ and purchased from Hunan in China. The terbium stock solution was prepared by dissolving weighed $\mathrm{Tb}_{4} \mathrm{O}_{7}$ in concentrated hydrochloric acid. The concentration of $\mathrm{Tb}^{3+}$ was standardized by complexometric titration with EDTA using xylenol orange as indicator in $\mathrm{HAc} / \mathrm{NaAc}$ buffer at $\mathrm{pH}$ 5.5. The solution of TNS prepared by dissolving weighed samples.

\subsection{Protein Expression and Purification}

Two proteins were used in this study, namely, EoCen (full-length of the wild type EoCen 1M-168Y), D37K (mutant EoCen with Asp37 changing to be Lys 1M$168 \mathrm{Y})$. The D37K was acquired by polymerase chain reaction technique with $\mathrm{p} 1$ (5'-TATTTAAGACCAAC AAAACTGG-3') and p2 (5'-AATCAAAGGCTTCTTT GATCTC-3') used as primers. Proteins of EoCen were over-expressed off a PGEX-6p-1 plasmid construct in Escherichia coli BL21 (DE3) induced with isopropyl-Dthiogalactopyranoside (IPTG) to yield milligram quantities of the desired protein as reported previously [18]. Briefly, transformed E. coli cells were grown in LB media containing $100 \mu \mathrm{g} / \mathrm{mL}$ ampicillin and incubated at $37^{\circ} \mathrm{C}$ while monitoring its growth via optical density (OD) measurements at $600 \mathrm{~nm}$. Once OD600 reaches 0.6, a final concentration of $0.5 \mathrm{mM}$ IPTG was added to the culture, and $3 \mathrm{~h}$ later, the cells were harvested and frozen. Frozen cells were thawed in PBS buffer and sonicated with a macro probe at mediate power on ice. This solution was centrifuged at $15,000 \mathrm{~g}$ for $25 \mathrm{~min}$ at $4{ }^{\circ} \mathrm{C}$. The supernatant was applied to a Glutathione-Sepharose TM 4B column which has been equilibrated with PBS buffer. After the initial purification by washing the supernatant with PBS buffer, prescissor proteinase was added at $4{ }^{\circ} \mathrm{C}$ for reacting about one night. Primary target proteins were washed out and eluted with PBS buffer. Then the proteins were applied to a superdex 75 column to be further purified. Fractions containing centrin were identified via 15\% SDS-PAGE (sodium dodecyl sulfate-polyacrylamide gel electrophoresis). After purification, the proteins were kept in $-80{ }^{\circ} \mathrm{C}$. The stock protein solutions were conserved in $10 \mathrm{mM}$ Hepes.

\subsection{Metal Lon Removal and Protein Concentration}

To remove contaminating bound cation, the protein samples were ultrafiltrated extensively against $10 \mathrm{mM}$ Hepes, pH 7.4 containing $1 \mathrm{mM}$ EDTA. The protein concentration was measured spectrophotometrically using molar extinction coefficient at $280 \mathrm{~nm}$ of $5600 \mathrm{~L} \cdot \mathrm{mol}^{-1} \cdot \mathrm{cm}^{-1}$. The extinction coefficient of centrin was estimated from the tyrosine content as previously reported [19].

\subsection{Native- and SDS-PAGE Assays}

Each protein sample with the same concentration was prepared in Hepes (10 mM, pH 7.4) for this experiment. Polyacrylamide gels contained $390 \mathrm{mM}$ Tris (pH 8.8), $10 \%$ ammonium persulfate, $15 \%$ acrylamide/bis (29:1), and $0.1 \%$ TEMED. Tris-glycine electrophoresis running buffer contained $25 \mathrm{mM}$ Tris $(\mathrm{pH} 8.3)$ and 250 $\mathrm{mM}$ glycine. All electrophoreses were run at room temperature. Gels were run at a constant current of $11-12 \mathrm{~mA}$ for $2 \mathrm{~h}$. Gels were fixed in $50 \%$ methanol, $7 \%$ acetic acid for $1 \mathrm{~h}$, washed in distilled water for $1 \mathrm{~h}$, stained with Coomassie blue R-250 for $2 \mathrm{~h}$, washed in distilled water for $2 \mathrm{~h}$.

For SDS-PAGE, keeping same experimental conditions as above described except that $10 \%$ sodium dodecyl sulfate (SDS) was added and running buffer contained $25 \mathrm{mM}$ Tris (pH 8.3), $250 \mathrm{mM}$ glycine, 10\% SDS was used. 


\subsection{Fluorescence Spectroscopy}

The changes of the hydrophobic exposure degree of wild type EoCen and D37K were studied by monitoring the fluorescence emission spectra of the hydrophobic probe TNS. The fluorescence spectra of TNS were measured by Cary Eclipse spectrofluorometer (Varian Inc.). The excitation wavelength was set at $320 \mathrm{~nm}$. The slit width of excitation and emission were both set at $10 \mathrm{~nm}$. Fluorescence emission spectra were recorded with a single scan over the range $350-600 \mathrm{~nm}$ for TNS. The protein solutions were prepared by dilution of the stock solution with $10 \mathrm{mM}$ Hepes pH 7.4 and $150 \mathrm{mM} \mathrm{KCl}$. The TNS stock solution was gradually added to the mixed solution. The mixture were shaken thoroughly, and then equilibrated for $3 \mathrm{~min}$ at $25^{\circ} \mathrm{C}$ in order to make the binding of TNS to protein was complete before measurements were taken.

\section{RESULTS AND DISCUSSIONS}

The effect of the mutation on the conformation of wild-type EoCen was monitored by Far-UV circular dichroism (CD), the Far-UV light CD spectra of EoCen and $\mathrm{D} 37 \mathrm{~K}$ are highly similar in shape (data not shown), which means that the mutation of aspartic acid does not disrupt the secondary structure of wild-type EoCen. Therefore, D37K was selected and purified for further research.

\subsection{SDS- and Native-PAGE Assays}

The mutant D37K had the same mobility as wild type EoCen on polyacrylamide gel electrophoresis in the presence of sodium dodecyl sulfate (Figure 2(a)), since the molecular weight of D37K nearly did not change after mutation with an apparent molecular mass of $20 \mathrm{kDa}$, indicating highly purified proteins were obtained. Figure 2(b) indicates that on the native PAGE, the position of $\mathrm{D} 37 \mathrm{~K}$ is higher than that of WT-EoCen which is much closer to the bottom of the gel (the positive pole), exhibiting the much more positive net charge of D37K that is obviously different from the SDS-PAGE (mutation of Asp37 does not disrupt the secondary structure shown in CD spectra), indicating that the mutate D37K is surely obtained.

\subsection{The Conformation Change of Proteins}

2-p-toluidinylnaphthalene-6-sulfonate (TNS) is a useful probe of conformational changes, because its fluorescence is altered when it binds to hydrophobic patches on the accessible surface of proteins [8,20,21]. Undergoing a large conformational change is required for the trigger proteins $\left(\mathrm{Ca}^{2+}\right.$-modulated proteins or sensor proteins such as $\mathrm{CaM}$ and troponin $\mathrm{C}$ ) to regulate a vast number of target proteins [22,23]. As shown in Figure 3, TNS had a weak fluorescence in water alone, and the fluorescence intensity increased largely with binding to EoCen and $\mathrm{Tb}^{3+}$-saturated EoCen, accompanied by a blue shift of the maximum fluorescence peak from 500 to $435 \mathrm{~nm}$, indicating the probe transferred from the polar to the apolar environment and the $\mathrm{Tb}^{3+}$-saturated centrin exposed more hydrophobic surface. Figure 4 is a set of fluorescence spectra caused by the addition of $\mathrm{Tb}^{3+}\left(3.35 \times 10^{4} \mathrm{M}\right)$ solution to $1.5 \mathrm{~mL}$ WT-EoCen $(8 \mu \mathrm{M})$ in the presence of TNS in $10 \mathrm{mM}$ Hepes at $\mathrm{pH} 7.4,150 \mathrm{mM}, 25^{\circ} \mathrm{C}$. The plot of the fluorescence intensity of TNS at $435 \mathrm{~nm}$ versus $\left[\mathrm{Tb}^{3+}\right] /[$ protein] is shown as Figure 5.
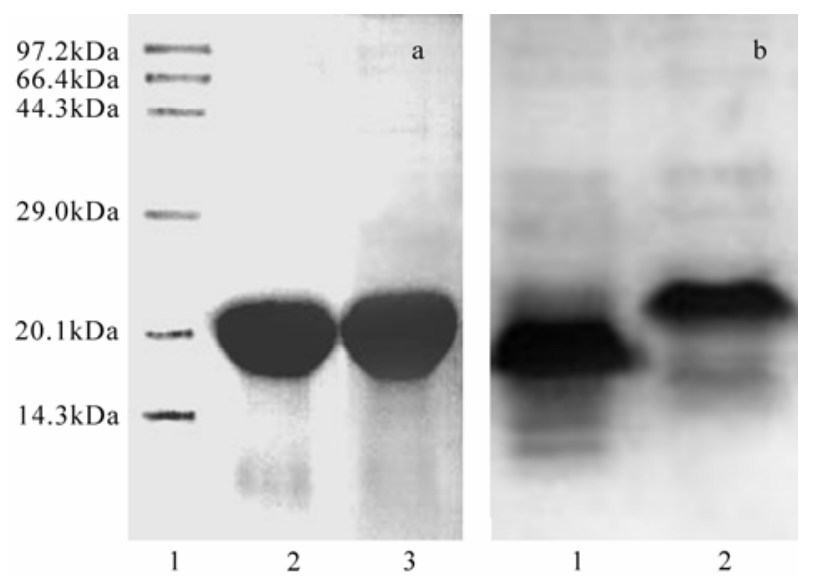

Figure 2. (a) The purified wild type apoEoCen and D37K monitored by $15 \%$ SDS-PAGE. Lane $1, \mathrm{Mr}$, molecular size marker; Lane 2, WT-EoCen; Lane 3, D37K. (b) The purified wild type apoEoCen and $\mathrm{D} 37 \mathrm{~K}$ monitored by $15 \%$ native PAGE. Lane 1, WT-EoCen; Lane 2, D37K.

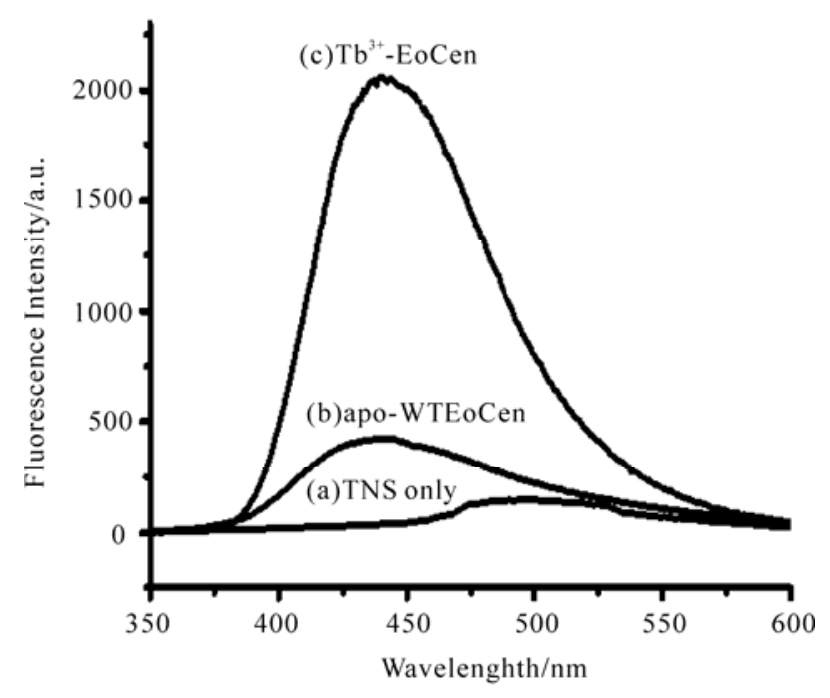

Figure 3. Fluorescence spectra of TNS alone (a); in the presence of apoEoCen (b); and $\mathrm{Tb}^{3+}$-saturated WT-EoCen (c). The protein concentration is $8 \mu \mathrm{M}$ in $10 \mathrm{mM}$ Hepes, $150 \mathrm{mM} \mathrm{KCl}$, at $\mathrm{pH} 7.4$ and $25^{\circ} \mathrm{C}$. 


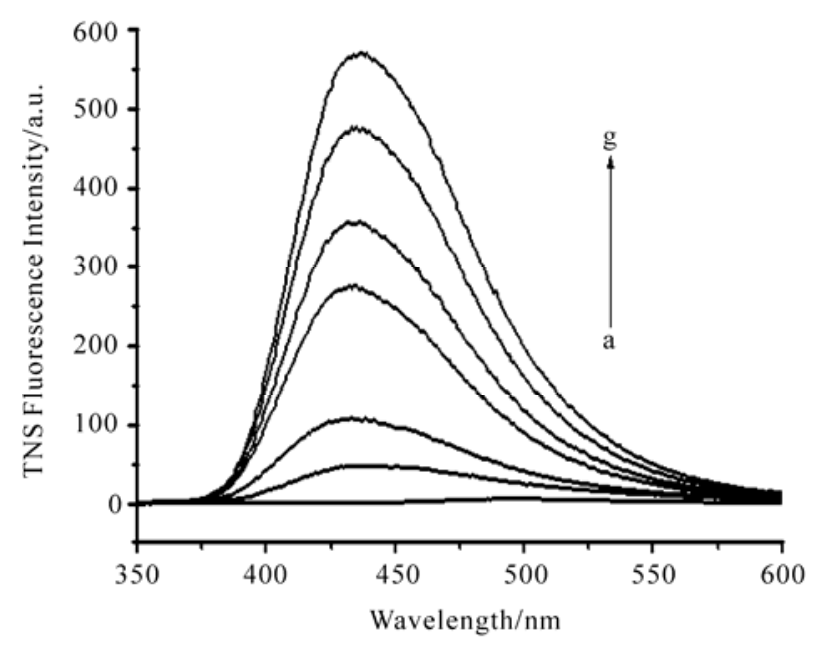

Figure 4. Fluorescence spectra of $\mathrm{Tb}^{3+}$ binding to EoCen in the presence of TNS. (a) $\left[\mathrm{Tb}^{3+}\right] /[\mathrm{P}]=0$; (b) $\left[\mathrm{Tb}^{3+}\right] /[\mathrm{P}]=1.0$; (c) $\left[\mathrm{Tb}^{3+}\right] /[\mathrm{P}]=2.0 ; \quad$ (d) $\left[\mathrm{Tb}^{3+}\right] /[\mathrm{P}]=2.5 ; \quad$ (e) $\left[\mathrm{Tb}^{3+}\right] /[\mathrm{P}]=3.0$; (f) $\left[\mathrm{Tb}^{3+}\right] /[\mathrm{P}]=3.5 ;(\mathrm{g})\left[\mathrm{Tb}^{3+}\right] /[\mathrm{P}]=4.0$. The protein concentration is $8 \mu \mathrm{M}$ in $10 \mathrm{mM}$ Hepes, $150 \mathrm{mM} \mathrm{KCl}$, at $\mathrm{pH} 7.4$ and $25^{\circ} \mathrm{C}$.

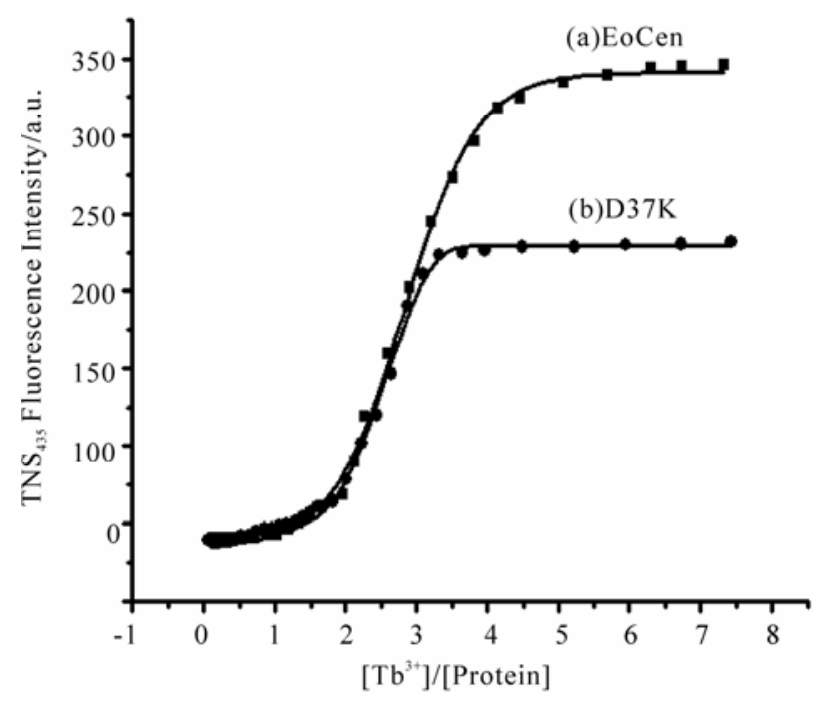

Figure 5. Titration curves of the addition $\mathrm{Tb}^{3+}$ to the WTEoCen and D37K in the presence of TNS, in 10mM Hepes, $\mathrm{pH}$ $7.4,25^{\circ} \mathrm{C}$. The protein concentration is $8 \mu \mathrm{M}$.

It can been seen from Figure 4 that there is a peak at near $435 \mathrm{~nm}$, and which increase obviously with the addition of metal ions, when the value of $\left[\mathrm{Tb}^{3+}\right] /[$ protein $]$ is equal to near 4 , the increase become very slow (Figure 5 , curve (a)). The conclusion, the affinities of sites IV and III (C-terminal domain) with $\mathrm{Tb}^{3+}$ are higher than that of sites I and II (N-terminal domain), has already obtained [24]. From Figure 4, the results show that EoCen undergo a conformational change when binding the $\mathrm{Tb}^{3+}$, and the change extent of hydrophobic exposure between the C-terminal domain and the N-terminal domain is different and the N-terminal domain is larger than the
C-terminal domain, induced by metal ions (Figure 5). So the C-terminal domain and N-terminal domain play a distinct role in the process of centrin realizing itself biological function. This is a possible explanation of that N-terminal of centrin responsible for self-assembly, while C-terminal serves as recognizing the target protein or enzyme, which is accord with the reports previously $[25,26]$. It can be seen from Figure 5 that D37K can only bind three equivalents $\mathrm{Tb}^{3+}$ (WT-EoCen binds four equiv. $\mathrm{Tb}^{3+}$ ). When Asp37, the first amino acid of loop I, was mutated to lysine, the net charge of loop I (in D37K) is changed from -1 to +1 . Due to the electrostatic repulsion between the positively charged loop and $\mathrm{Tb}^{3+}$, the metal-binding ability of loop I in D37K is abolished. TNS fluorescence intensity induced by the $\mathrm{Tb}^{3+}$ binding to $\mathrm{D} 37 \mathrm{~K}$ is obviously declined. It can be concluded that the mutation of Asp to Lys at position 37 leads to the smaller exposure of hydrophobic surface in the presence of $\mathrm{Tb}^{3+}$, which can be attributed to the fact that the ability of metal-binding of loop I was abolished by mutation of Asp37 to lysine. It proved that the Asp37 plays an important role in maintaining the proper conformation of EoCen in the presence of $\mathrm{Tb}^{3+}$.

\subsection{The Calculation of the Binding Constants of TNS Interaction with $\mathrm{Tb}^{3+}$-Loaded Proteins}

Assuming that there are $n$ TNS-binding sites and they are independent and identical in TNS-protein complex, the conditional binding constants [27-29] can be fitted using Eqs.1-6 from the data of curves a and b in Figure 6.

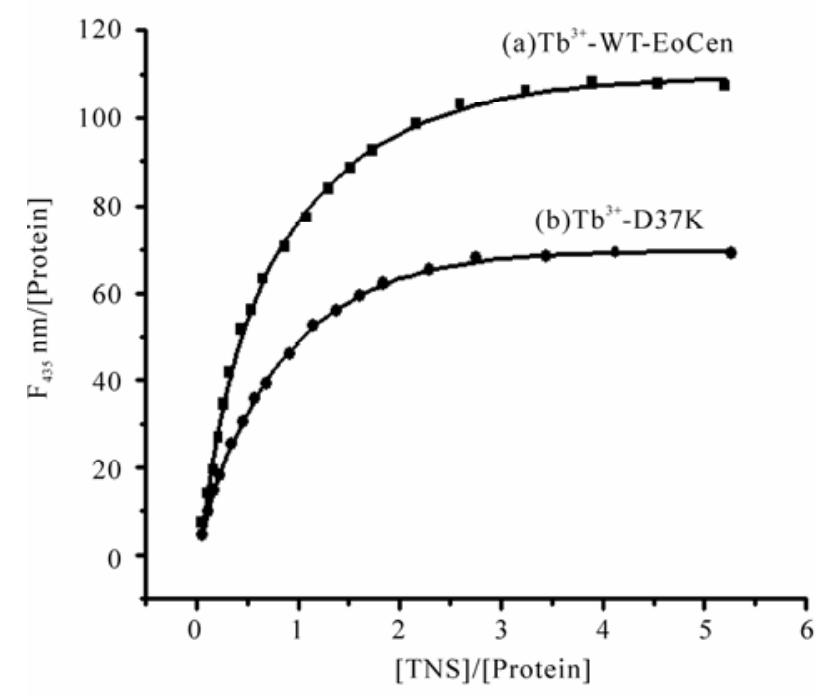

Figure 6. Titration curves of the addition TNS to the different form of proteins, in $10 \mathrm{mM}$ Hepes, $150 \mathrm{mM} \mathrm{KCl}, \mathrm{pH} \mathrm{7.4,25}{ }^{\circ} \mathrm{C}$. (a) $\mathrm{Tb}^{3+}$-saturated WT-EoCen, (b) $\mathrm{Tb}^{3+}$-saturated $\mathrm{D} 37 \mathrm{~K}$. The protein concentration is $8 \mu \mathrm{M}$. 
The binding equation is presented by:

$$
n \mathrm{TNS}+\mathrm{P} \leftrightarrow \mathrm{TNS}_{n} \mathrm{P}
$$

Given that $\mathrm{F}_{\infty}$ is maximum molar fluorescence intensity, $F_{r}$ is fluorescence intensity of every titration dot. The increase of fluorescence intensity resulted from the binding of TNS to protein. The following equations can be obtained:

$$
\begin{aligned}
& F_{\infty} \propto n[\mathrm{P}]_{\mathrm{t}} \\
& \mathrm{F}_{\mathrm{r}} \propto[\mathrm{TNS}]_{\mathrm{b}} \\
& {[\mathrm{TNS}]_{\mathrm{b}}=\frac{F_{\mathrm{r}} \cdot n[\mathrm{P}]_{\mathrm{t}}}{F_{\infty}} }
\end{aligned}
$$

where $[\mathrm{TNS}]_{\mathrm{b}}$ is the bound concentration of TNS. $[\mathrm{P}]_{\mathrm{t}}$ and $[\mathrm{P}]_{\mathrm{b}}$ is the total and bound concentration of protein in 10 $\mathrm{mM}$ Hepes, $\mathrm{pH} 7.4,25{ }^{\circ} \mathrm{C}$, respectively. The binding constant can be given as follows:

$$
K=\frac{[\mathrm{TNS}]_{\mathrm{b}}}{[\mathrm{TNS}]_{\mathrm{f}} \cdot n[\mathrm{P}]_{\mathrm{f}}}
$$

$[T N S]_{\mathrm{f}}$ and $[\mathrm{P}]_{\mathrm{f}}$ represent the free concentration of TNS and protein, respectively. Finally, equation can be expressed by Eq.6.

$$
\frac{[\mathrm{TNS}]_{\mathrm{t}}}{[\mathrm{TNS}]_{\mathrm{b}}}=1+\frac{1}{K\left\{n[\mathrm{P}]_{\mathrm{t}}-[\mathrm{TNS}]_{\mathrm{b}}\right\}}
$$

For $\mathrm{Tb}^{3+}$-EoCen, $1 / \mathrm{K}$ can be obtained by the linear slope of the plot of $[\mathrm{TNS}]_{\mathrm{t}} /[\mathrm{TNS}]_{\mathrm{b}}$ versus $\left\{\left[\mathrm{Tb}^{3+}-\mathrm{EoCen}\right]_{\mathrm{t}}-\right.$ $\left[\mathrm{TNS}_{\mathrm{b}}\right\}^{-1}$, as showed in Figure 7. $n$ is set to be 1, the intercept of Eq.6 is very close to 1, and can also be seen in Figure 6, $n=1$ is suitable. $\mathrm{K}\left(\mathrm{Tb}^{3+}\right.$-EoCen-TNS) can be calculated to be $(7.38 \pm 0.25) \times 10^{5} \mathrm{M}^{-1}$ from Figure 7 . In the similar way, $\mathrm{K}\left(\mathrm{Tb}^{3+}\right.$-D $\left.37 \mathrm{~K}-\mathrm{TNS}\right)$ can be calculated to be $(1.16 \pm 0.05) \times 10^{6} \mathrm{M}^{-1}$.

It can be seen that the affinities of TNS binding to EoCen and D37K are different, $\mathrm{K}\left(\mathrm{Tb}^{3+}\right.$-D37K-TNS $)>\mathrm{K}$ $\left(\mathrm{Tb}^{3+}\right.$-EoCen-TNS), showing that $\mathrm{D} 37 \mathrm{~K}$, with more positive charges, has larger electrostatic interaction with TNS than EoCen in the presence of $\mathrm{Tb}^{3+}$ and the mutation of Asp37 influence the hydrophobic and electrostatic environment of WT-EoCen.

\section{CONCLUSIONS}

Using the fluorescence spectroscopy, the interaction of TNS and EoCen has been studied in the presence of $\mathrm{Tb}^{3+}$. WT-EoCen and D37K undergo a different extent conformation change, and $\mathrm{D} 37 \mathrm{~K}$ exposes lesser hydrophobic surface in the presence of $\mathrm{Tb}^{3+}$, which can be attributed to the fact that the ability of metal-binding of site I was abolished by the mutation of Asp37 to lysine. It can be concluded that the Asp37 plays an important role in maintaining the proper conformation of EoCen in the

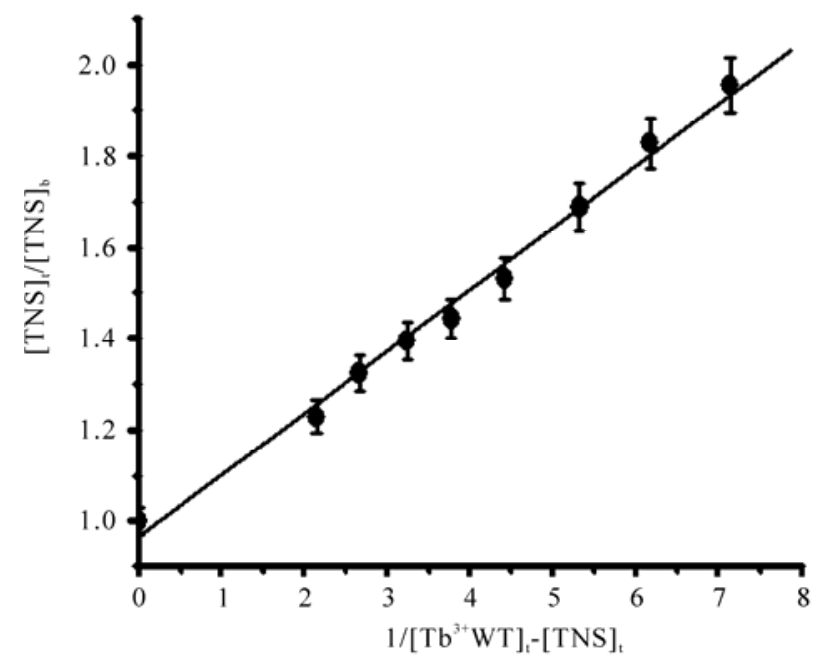

Figure 7. The plot of $[\mathrm{TNS}]_{\mathrm{t}} /[\mathrm{TNS}]_{\mathrm{b}}$ vs $\left\{[\mathrm{WT}-\mathrm{EoCen}-\mathrm{Tb}]_{\mathrm{t}}[\mathrm{TNS}]_{\mathrm{b}}\right\}^{-1}$.

presence of $\mathrm{Tb}^{3+}$. In the end, the binding constants of TNS with $\mathrm{Tb}^{3+}$-saturated EoCen and $\mathrm{D} 37 \mathrm{~K}$ were obtained, $\mathrm{K}\left(\mathrm{Tb}^{3+}\right.$-EoCen-TNS $)=(7.38 \pm 0.25) \times 10^{5} \mathrm{M}^{-1}$ and $\mathrm{K}\left(\mathrm{Tb}^{3+}\right.$ $-\mathrm{D} 37 \mathrm{~K}-\mathrm{TNS})=(1.16 \pm 0.05) \times 10^{6} \mathrm{M}^{-1}$.

\section{ACKNOWLEDGEMENTS}

We acknowledge to the financial support of this work by the National Natural Science Foundation of P.R. China (Nos. 20771068 and 20901048) and the Natural Science Foundation Shanxi Province (No. 2007011024).

\section{REFERENCES}

[1] Thompson, J.R., Ryan, Z.C., Salisbury, J.L. and Kumar, R. (2006) The structure of the human centrin 2-xeroderma pigmentosum group $\mathrm{C}$ protein complex. Journal of Biological Chemistry, 281, 18746-18752.

[2] Lingle, W.L., Lutz, W.H., Ingle, J.N., et al. (1998) Centrosome hypertrophy in human breast tumors: Implications for genomic stability and cell polarity. Proceedings of the National Academy of Sciences USA, 95, 2950-2955.

[3] Jaspersen, S.L. and Winey, M. (2004) The budding yeast spindle pole body: Structure, duplication, and function. Annual Review of Cell and Developmental Biology, 20, 1-28.

[4] Lingle, W.L., Barrett, S.L., Negron, V.C., et al. (2002) Centrosome amplification drives chromosomal instability in breast tumor development. Proceedings of the National Academy of Sciences USA, 99, 1978-1983.

[5] Lingle, W.L. and Salisbury, J.L. (1999) Alter centrosome structure is associated with abnormal mitoses in human breast tumors. American Journal of Pathology, 155, 1941-1951.

[6] Lingle, W.L. and Salisbury, J.L. (2000) The role of the centrosome in the development of malignant tumors. Current Topics in Developmental Biology, 49, 313-329.

[7] Yang, A., Miron, S., Mouawad, L., et al. (2006) Flexibility and plasticity of human centrin 2 binding to the xeroderma pigmentosum group $\mathrm{C}$ protein (XPC) from nuclear exci- 
sion repair. Biochemistry, 45, 3653-3663.

[8] Li, G.T., Wang, Z.J., Zhao, Y.Q., et al. (2007) The spectral studies on the effect of Glu 101 to the metal binding characteristic of Euplotes octocarinatus centrin. Spectrochim Acta A, 67, 1189-1193.

[9] Wiech, H.B., Geier, M., Paschke, T., et al. (1996) Characterization of green alga, yeast, and human centrins. Journal of Biological Chemistry, 271, 22453-22461.

[10] Cox, J.A., Tirone, F., Durussel, I., et al. (2005) Calcium and magnesium binding to human centrin 3 and interaction with target peptides. Biochemistry, 44, 840-850.

[11] Wang, Z.J., Ren, L.X., Zhao, Y.Q., et al. (2007) Metal ions-induced conformational change of $\mathrm{P}_{23}$ by using TNS as fluorescence probe. Spectrochim Acta Part A, 66, $1323-1326$.

[12] Wang, Z.J., Ren, L.X., Zhao, Y.Q., et al. (2008) Investigation on the binding of TNS to centrin: An EF-hand protein. Spectrochim Acta Part A, 70, 892-897.

[13] Weber, C.V., Lee, D., Chazin, W.J. and Huang, B. (1994) High level expression in Escherichia coli and characterization of the EF-hand calcium-binding protein caltractin. Journal of Biological Chemistry, 269, 15795-15802.

[14] Rigden, D.J. and Galperin, M.Y. (2004) The DxDxDG Motif for calcium binding: Multiple structural contexts and implications for evolution. Journal of Biological Chemistry, 343, 971-984.

[15] Hu, J., Jia, X., Li, Q., et al. (2004) Binding of $\mathrm{La}^{3+}$ to calmodulin and its effects on the interaction between calmodulin and calmodulin binding peptide, polistes mastoparan. Biochemistry, 43, 2688-2698.

[16] Shannon, R.D. (1976) Revised effective ionic radii and systematic studies of interatomic distances in halides and chalcogenides. Acta Crystallographica A, 32, 751-767.

[17] Bai, H.J., Liu, W. and Yang, B.S. (2002) Fluorescence studies on the kinetics of terbium (III) removal from monoterbium transferrins by tartaric acid. Acta Chimica Sinica, 60, 1253-1257.

[18] Duan, L., Zhao, Y.Q., Wang, Z.J., et al. (2008) Lutetium (III)-dependent self-assembly study of ciliate Euplotes octocarinatus centrin. Journal of Inorganic Biochemistry,
102, 268-277.

[19] Pace, C.N., Vajdos, F., Fee, L., et al. (1995) How to measure and predict the molar absorption coefficient of a protein. Protein Science, 4, 2411-2423.

[20] McClure, W.O. and Edelman, G.M. (1966) Fluorescent probes for conformational states of proteins. I. Mechanism of fluorescence of 2-p-Toluidinylnaphthalene-6-sulfonate: A hydrophobic probe. Biochemistry, 5, 1908-1919.

[21] Durussela, I., Blouquitb, Y., Middendorpc, S., et al. (2000) Cation- and peptide-binding properties of human centrin 2 . FEBS Letters, 472, 208-212.

[22] Ikura, M., Clore, G.M., Gronenborn, A.M., et al. (1992) Solution structure of a calmodulin-target peptide complex by multidimensional NMR. Bax Science, 256, 632-638.

[23] Zhang, M., Tanaka, T. and Ikura, M. (1995) Calciuminduced conformational transition revealed by the solution structure of apo calmodulin. Nature Structural Biology, 2, 758-767.

[24] Wang, Z.J., Zhao, Y.Q., Ren, L.X., et al. (2007) Spectral study on the interaction of ciliate Euplotes octocarinatus centrin and metal ions. Journal of Photochemistry and Photobiology A, 186, 178-186.

[25] Hu, H.T. and Chazin, W.J. (2003) Unique features in the C-terminal domain provide caltractin with target specificity. Journal of Biological Chemistry, 330, 473-484.

[26] Tourbez, M., Firanescu, C., Yang, A., et al. (2004) Calcium-dependent self-assembly of human centrin 2 . Journal of Biological Chemistry, 279, 47672-47680.

[27] Ren, L. X., Zhao, Y.Q., Feng, J.Y., et al. (2006) Terbiumand calcium-binding properties of N-terminal domain of Euplotes centrin. Chinese Journal of Inorganic Chemistry, 22, 87-90.

[28] Yang, B.S., Liu, W., Ren, L.X., et al. (2009) The spectral studies on the metal binding characteristic of N-terminal domain of ciliate Euplotes octocarinatus centrin. Journal of Shanxi University (Nature and Science Edition), 32(4), 572-576.

[29] Yang, B.S., Yang, P. and Song, L.H. (1984) The binding of Gd (III) to human serum albumin. Chinese Science Bulletin, 29, 1502-1505. 